\title{
DINÂMICA ESPAÇO-TEMPORAL NA DISSEMINAÇÃO DA COVID-19 EM NITERÓI (RJ): UMA CONTRIBUIÇÃO GEOGRÁFICA NA FASE INICIAL DA PANDEMIA
}

\section{Space-temporal dynamics in the dissemination of covid-19 in Niterói (RJ): a geographical contribution in the initial phase of pandemic}

\author{
Thiago dos Santos Leal \\ Doutorando do Progr. de Pós-Graduação em Geografia da UFRJ \\ thiagolealgeo@gmail.com \\ Otávio Miguez da Rocha Leão \\ Professor Associado do Departamento de Geografia da UERJ-FFP \\ orochaleao@hotmail.com \\ Rafael Silva de Barros \\ Professor Associado do Departamento de Geografia da UFRJ \\ rafael.barros@igeo.ufrj.br \\ Pedro Octávio Bittencourt de Rezende \\ Graduado em Engenharia Ambiental na UFF \\ pedrobittencourt@id.uff.br
}

Artigo enviado para publicação em 27/04/2020 e aceito em 01/05/2020

DOI: $10.12957 /$ tamoios.2020.50510

\begin{abstract}
Resumo
A Organização Mundial da Saúde (OMS) declarou em janeiro de 2020 que o surto da nova cepa de coronavírus - classificada como SARS-CoV-2 cuja doença foi denominada de covid-19 - constitui uma Emergência de Saúde Pública de Importância Internacional. Neste contexto, o presente estudo tem por objetivo elencar as contribuições geográficas no âmbito intrametropolitano da pandemia de covid-19 na cidade de Niterói-RJ, a partir da dinâmica espaço-temporal e de variabilidade de indicadores sociais. Foram realizados, para os períodos de 11/03/20 a 08/04/20 e de 11/03/20 a 17/04/20, o levantamento de dados acerca da covid-19, a espacialização dos dados multitemporais no município, por bairro, e uma análise de diferentes critérios - ponderando a densidade de casos, os eixos principais de dispersão, rendimento por bairro, número de idosos por bairro e situação hospitalar - a fim servir como subsídio e auxiliar no desenvovimento de políticas públicas. Como resultado há a indicação entre o período até 08/04/20 e 17/04/20 da tendência de disseminação seguindo eixos de circulação viária, alta densidade de casos confirmados na região norte e praias da baía do município. O bairro de Icaraí é o maior em número de casos entre 08/04/20 e 17/04/20 apresentou um crescimento de casos confirmados em termos percentuais de $60 \%$.
\end{abstract}

Palavras-chave: covid-19; disseminação; indicadores sociais.

\begin{abstract}
The World Health Organization (WHO) declared in January 2020 that the new coronavirus strain outbreak - classified as SARS-CoV-2 whose disease named as covid-19 - constitutes a Public Health Emergency of International Importance. In this context, the present study aims to describe the geographic contributions in the intra-metropolitan scenario of the covid-19 pandemic in Niterói city-RJ, based on space-time dynamics and variability of social indicators. For periods from $03 / 11 / 20$ to $04 / 08 / 20$ and from $03 / 11 / 20$ to $04 / 17 / 20$, we performed covid-19's data collection, spatial analysis of multitemporal data by neighborhood division and a different criteria analysis considering cases density, main axes of dispersion, the income per neighborhood, the number of elderly people per neighborhood and the hospital situation, for subsidizing public policies development. As a result, there is an indication between the period up to 04/08/20 and 04/17/20 of a trend of spread following axes of road circulation, a high density of confirmed cases in the Northern and Beaches of Bay administrative regions of the municipality. Icaraí neighborhood is the highest in number of confirmed cases and between 04/08/20 and 04/17/20 showed an increase of 60\%.
\end{abstract}

Keywords: covid-19; dissemination; social indicators. 


\section{Introdução}

A introdução e transmissão precoce do SARS-CoV-2 (o coronavírus que causa a covid-19) no mundo e também no Brasil se configura como um grande problema sanitário e econômico. O primeiro caso deste tipo de coronavírus foi detectado no Brasil em fevereiro de 2020, na maior metrópole brasileira, São Paulo. E em 05 de março de 2020 foi confirmado o primeiro caso de covid-19 na segunda maior metrópole nacional, Rio de Janeiro. Segundo boletim diário do Ministério da Saúde (2020) sobre covid-19 até 22 de abril de 2020, o número de casos confirmados em São Paulo era de 15385 com 1093 óbitos e no Rio de Janeiro 5306 com 461 óbitos.

Niterói, que está inserido na região metropolitana do Rio de Janeiro, apresentou o primeiro caso com quadro médico de sintomas da covid-19 no dia 11/03/2020, e até 22 de abril apresentava 242 casos confirmados e 16 óbitos. No momento da publicação desse artigo os números poderão ser bem maiores devido à rapidez com que está ocorrendo a propagação do vírus e o aumento do número de testagem.

Identificar os focos, indicar possíveis causas e estabelecer medidas mitigadoras é um esforço relevante para contenção do avanço de uma pandemia, requerendo a análise de um complexo conjunto de dados sociais, ambientais e epidemiológicos, especialmente em sua dimensão espacial, presentes no território.

A Geografia no decorrer do tempo tem consolidado sua importância no combate a epidemias, contribuindo para estabelecer hipóteses causais e propor medidas mitigantes. Dentre as inúmeras contribuições que podem ser citadas há a de Louis René de Villemé (1782-1863) o qual pesquisou as doenças dos trabalhadores das indústrias de algodão, seda e lã demonstrando as relações de causalidade entre exposição ocupacional das anilinas e a produção de câncer de bexiga em trabalhadores. O médico John Snow, em 1855, em Londres, utilizou análise geográfica para identificar a fonte da epidemia de cólera que assolava a cidade, realizando um mapeamento dos casos da doença e dos poços de água numa parte de Londres. A partir de tais análises deduziu que a transmissão da doença ocorria por meio da água ingerida contaminada e, por isso, ordenou o fechamento do poço que seria a principal fonte de contaminação. Com esta atitude reduziu a epidemia.

$\mathrm{Na}$ atualidade muitas autoridades públicas têm indicado que a covid-19 está diretamente ligada à estrutura etária e à densidade demográfica de um determinado lugar. No entanto Ferrão (2020) indica que é necessário distinguir exposição, suscetibilidade e vulnerabilidade. Sendo a origem do coronavírus externa ao país, o conceito de exposição define-se, numa primeira fase, em função do grau de abertura de cada território ao exterior. Por exemplo, as áreas metropolitanas, as regiões exportadoras, as regiões com dinâmicas transfronteiriças mais intensas ou as áreas que mantêm uma circulação regular de pessoas com comunidades emigrantes estão mais expostas à possibilidade de importação de vírus. Mas as características de cada um desses tipos de territórios são diferenciadas sob muitos pontos de vista, das características sociodemográficas e habitacionais das populações que aí residem à oferta de serviços de saúde.

A suscetibilidade está relacionada à predisposição ou propensão de um determinado lugar à proliferação do patógeno. Segundo Carvalho (2014) a suscetibilidade indica a potencialidade de ocorrência de processos naturais e induzidos em uma dada área, expressando-se segundo classes de probabilidade de ocorrência e se caracterizando pela predisposição dos terrenos em desenvolverem processos de contenção ou propagação de mudanças relacionadas aos vetores de distúrbio.

Já a vulnerabilidade, segundo Castro, Peixoto \& Rio (2005) indica a probabilidade de que uma vida seja perdida, em um determinado grupo humano que pode ser afetado pelo processo considerado. 
Desta forma é possível que, devido à variação geográfica, duas áreas com mesmo grau de exposição a focos externos apresentem suscetibilidades e vulnerabilidade distintas.

A vulnerabilidade de uma determinada área é estruturada a partir do número de casos e o potencial para evolução da gravidade da doença. E isso pode sofrer modificações no decorrer do ciclo epidemiológico, principalmente quando a exposição externa é controlada, como a diminuição de voos internacionais por exemplo.

Ao se estudar os fatores que contribuem na suscetibilidade e vulnerabilidade de uma determinada área podem ser percebidas tendências de disseminação, ajudando na compreensão do fenômeno.

Para além da variação geográfica, o tempo também é um fator central na análise da dinâmica em uma pandemia viral, uma vez que indica a velocidade de disseminação. Enquanto que para análises de fenômenos geológicos os estudos podem ser datados de milhões de anos, em uma pandemia viral a peridodização na ordem de dias se mostra adequada tendo em vista a rapidez da proliferação da doença e a consequente sobrecarga dos sistemas de saúde, podendo instaurar um quadro de colapso.

Diante da complexidade da pandemia e suas diferentes configurações espaciais, faz-se necessário estudos de escala com grande detalhamento buscando avaliar o aumento da covid-19 no território, nos bairros e nos municípios. Os estudos de escala nacional e regional pelo seu grande aporte de área muitas vezes promovem generalizações de características que podem ser relevantes no controle da pandemia, sendo estudos de escala local importantes para melhor entendimento da disseminação.

Logo, o presente trabalho objetiva elencar as contribuições geográficas no contexto intrametropolitano da pandemia de covid-19 na cidade de Niterói (RJ), a partir da dinâmica espaço-temporal, e avaliar a variabilidade dos indicadores sociais nos bairros de Niterói e suas relações com a propagação na fase inicial da pandemia, demonstrando a interface desses fatores com a suscetibilidade e vulnerabilidade da área estudada.

\section{Área de estudo}

De acordo com o Atlas do Desenvolvimento Humano do Brasil (2013), baseado no censo de 2010 e elaborado pelo Programa das Nações Unidas para o Desenvolvimento (Pnud), Niterói é o primeiro município no ranking de índice de desenvolvimento humano (IDH) no estado do Rio de Janeiro e o sétimo no ranking em âmbito nacional. Segundo IBGE (2020) a população estimada para esta cidade atualmente é de 513 mil habitantes.

O município de Niterói está inserido na região metropolitana do estado do Rio de Janeiro fazendo limite ao norte com o município de São Gonçalo e a leste com o Município de Maricá (Figura 1). São Gonçalo aparece na $795^{a}$ posição no ranking de IDH no Brasil com população estimada pelo IBGE (2020) de 1.084.839 habitantes. E Maricá em $289^{\circ}$ lugar no ranking de IDH no Brasil, apresentando um total estimado de com 161.000 habitantes. 


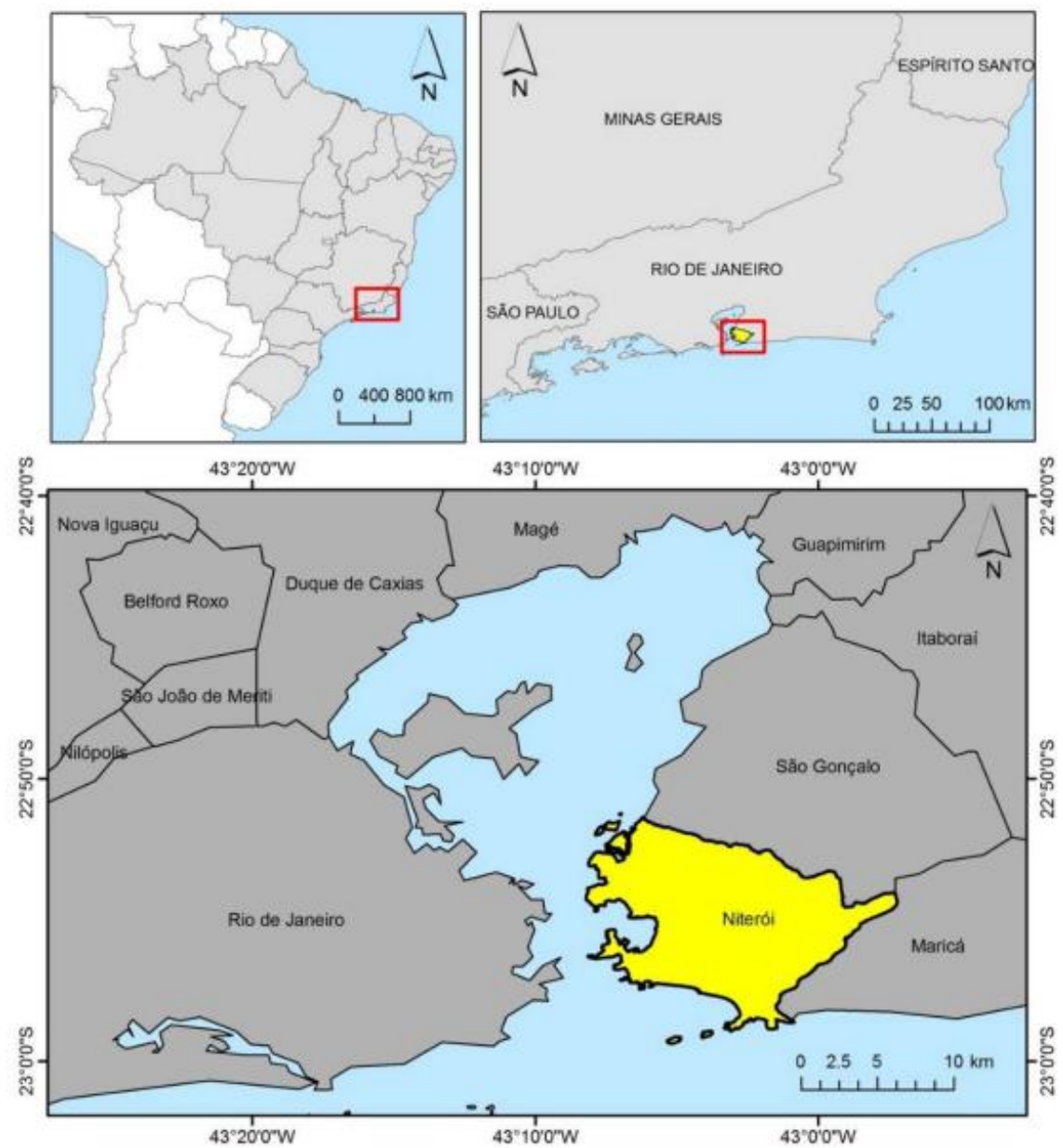

Figura 1 - Localização da área de estudo

Fonte: Seabra et al. (2015).

\section{Materiais e métodos}

O desenvolvimento da presente pesquisa foi baseada nas seguintes etapas: 1) levantamento de dados relacionados à covid-19 em Niterói (hospitalizados em enfermaria, hospitalizados em UTI, óbitos, casos confirmados, $\mathrm{n}^{\circ}$ de casos curados, bairro de ocorrência por data, casos por faixa etária); 2) Espacialização dos dados multitemporais no município por bairro até o dia 08/04/20 e até o dia 17/04/20; 3) Análise de diferentes critérios (densidade de casos, eixos principais de dispersão, rendimento por bairro e número de idosos por bairro) da ocorrência dos casos da covid-19 como subsídio ao desenvolvimento de políticas públicas, indicando a interface desses fatores com a suscetibilidade e vulnerabilidade de determinada área.

Foi tomado como base o dia 11/03/20 pois foi quando se iniciou o sintoma de covid-19 do primeiro caso noticiado nos meios de comunicação. E o dia 08/04/20 como referência para o primeiro período analítico devido a ser o primeiro boletim diário de covid-19 divulgado por canal oficial da prefeitura com os dados espacializados por bairro.

É relevante esclarecer que houve a necessidade de levantar o número de casos por bairro no município limítrofe de São Gonçalo devido a sua grande população absoluta (mais de um milhão de habitantes), alta densidade demográfica, aumento do número de casos de covid-19 até o dia 08/04/20 (recorte temporal) e a interação funcional entre as 
duas cidades (desde relações trabalhistas, de trabalho formal e informal, até utilização da infraestrutura de saúde), caracterizando uma rede urbana conurbada com grande ocorrência de migração pendular. Assim foi realizada a análise temporal de densidade de casos por bairro compreendendo os dias dos boletins até o 8/4/20, até o dia 13/04/20 e até o dia 17/04/20 nos dois municípios buscando melhor caracterizar a evolução da densidade de casos confirmados. Para tanto foi utilizado o programa Arcgis 10.5®, a partir da extensão Spatial Analyst Tools, ferramenta "Kernel density”, com tamanho de célula de 60 e raio de $0,5 \mathrm{Km}$. Estes limiares foram estabelecidos após suscessívas tentativas buscando melhor representatividade. Cabe esclarecer que os pontos plotados levaram em consideração o bairro e não a residência da pessoa que contraiu a covid-19, sendo esta uma informação indisponível.

$\mathrm{Na}$ análise de evolução de casos entre o dia 8/4/20 e o dia 17/4/20, foi realizada a subtração do número de casos por bairro do dia 17 menos os do dia 8 . Com a finalidade de classificação do resultado foi utilizado o método padrão quebras naturais (jenks).

Para levantamento dos casos de covid-19 foram utilizadas variadas fontes como: notícias de jornais, dados disponibilizados da Secretaria de Saúde do estado do Rio de Janeiro online no site (http://painel.saude.rj.gov.br) e boletins diários da Prefeitura de Niterói e de São Gonçalo disponíveis nas redes sociais, conforme a figura 2.
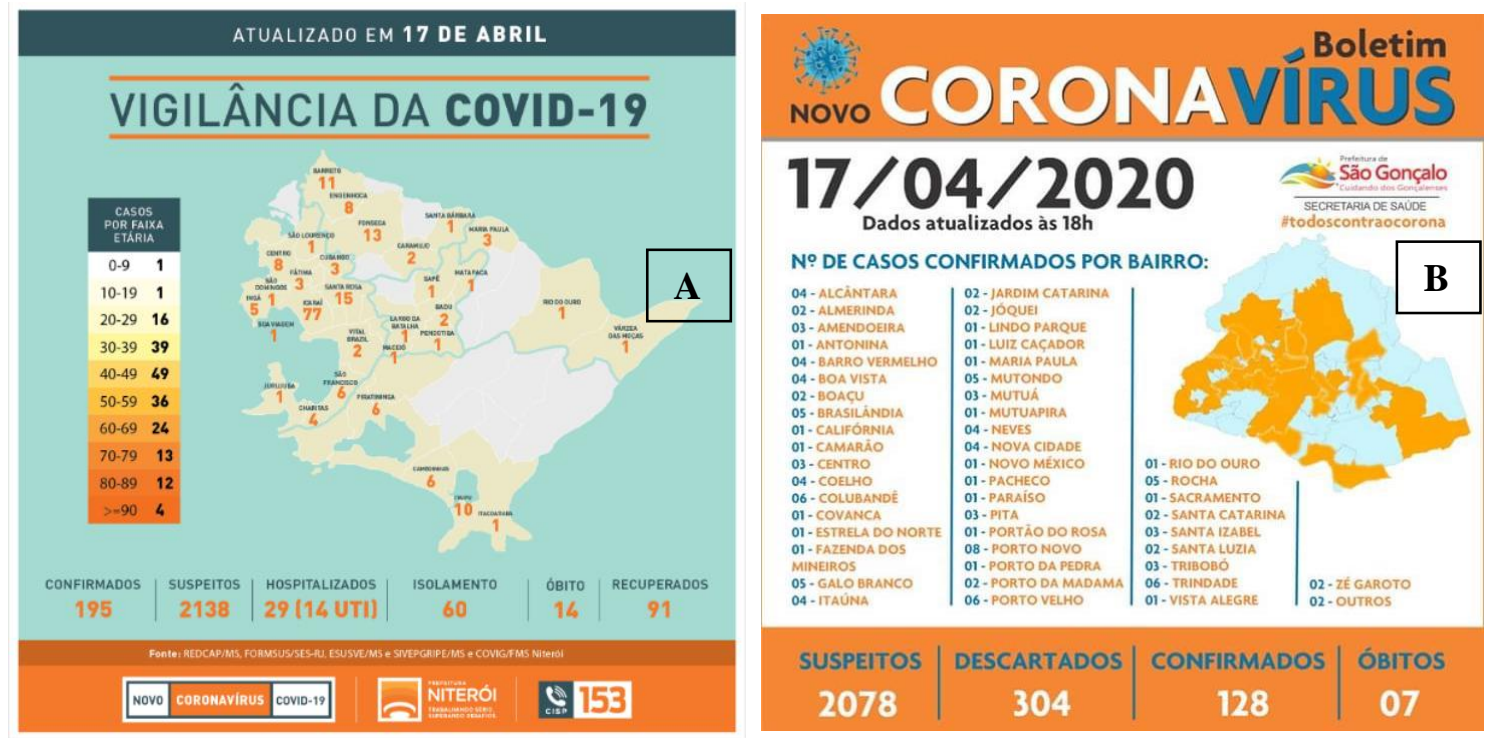

Figura 2: Exemplos de boletins diários disponibilizados pela prefeitura de Niterói (A) e de São Gonçalo (B).

Fonte: Acervo fotográfico dos autores.

\section{Resultados e discussões}

\section{A geografia no contexto da pandemia: dinâmica espaço-temporal}

O primeiro caso registrado de covid-19 em Niterói ocorreu em março de 2020. Desde então, a prefeitura do município iniciou a publicação de um boletim informativo diário dispondo sobre a disseminação do vírus na cidade.

No dia 19 de março foram publicados pelo prefeito de Niterói, os decretos de $\mathrm{n}^{\circ} 13513 / 2020, \mathrm{n}^{\circ} 13516 / 2020$ e $\mathrm{n}^{\circ} 13517 / 2020$, que consolidaram o início da política de distanciamento social adotado pela cidade, com a finalidade de conter o avanço do contágio do vírus. Dois dias após a confirmaçao do primeiro óbito decorrente da covid- 
19.

Nesta fase incial da covid-19 em Niterói é importante conhecer o padrão espacial da doença, identificar os bairros que concentraram os casos iniciais e compreender a tendência de avanço da doença. Para isso foram mapeados os casos notificados até 8/4/2020 e até 17/4/2020, como mostram as figuras 3 e 4, a seguir. $\mathrm{Na}$ primeira data havia 108 casos confirmados da doença, além de outros 1.126 casos suspeitos. São Gonçalo apresentava 45 casos confirmados. Na segunda data o número de casos confirmados havia aumentado para 197, além de 2.138 casos suspeitos. Em São Gonçalo o número de casos confirmados havia mais do que dobrado, com 128 registros em 17/04/2020.

Destaca-se que o boletim diário apresentou uma pequena divergência no número de casos, pois somados os casos de confirmados por bairro no dia 08/04/20 o resultado é 108 e não 107 como é mostrado no canto inferior esquerdo, conforme figura 5. Houve decisão por usar como referência o número dos bairros por ser mais específica e atender melhor aos objetivos deste trabalho.

$\mathrm{Na}$ figura 3 pode-se perceber que os bairros que concentravam as maiores quantidades de casos estavam localizados, até o dia 8/4/2020, na porção norte/noroeste do município de Niterói, com uma grande concentração de doentes (48 casos) em Icaraí - um outlier naquele momento, já que o $2^{\circ}$. bairro em número de casos - Fonseca apresentava 8 doentes. Icaraí concentra o maior número de idosos (18.852) no município. Além de Icaraí, os outros dois bairros com maiores números de casos (Fonseca e Santa Rosa) também são os $2^{\circ}$ e $3^{\circ}$. E quantidade de idosos (8.392 e 5.093, respectivamente).

Dos 52 bairros de Niterói, 31 ainda não apresentavam nenhum caso confirmado de covid-19 e somente Icaraí apresentava mais de 8 casos, demonstrando uma concentração do problema naquele momento.

Outros 3 bairros com maiores ocorrências da doença detacam-se no mapeamento apresentado na Figura 3. Barreto, com 7 casos, que marca um importante limite entre São Gonçalo e Niterói, por onde há uma grande conectividade entre os municípios. Fonseca, com 8 casos, fica muito próximo ao Barreto, e é separado dele pelo bairro Engenhoca cujos tecidos urbanos são conectados. Santa Rosa apresentava 6 casos confirmados e é um bairro vizinho a Icaraí.

O mapeamento dos casos confirmados de covid-19 apresentado na Figura 4 mostra um significativo avanço da doença tanto em número de casos confirmados (passando de 108 para 197) quanto no número de suspeitos (1.126 para 2.138). Em termos espaciais, também há uma efetiva ampliação: na segunda data a doença já alcançava 31 dos 52 bairros de Niterói.

O mapa da figura 6 apresenta o mapeamento do crescimento do número de casos, ou seja, da diferença na quantidade de casos entre 17/4/2020 e 8/4/2020. Percebe-se, espacialmente, em quais bairros e partes da cidade o número de casos mais cresceu. Ainda que retrate um intevalo de tempo pequeno e, de certa forma, uma fase inicial da pandemia no município de Niterói, esta espacialização é importante de ser feita ao longo de todo o tempo de evolução da doença, a fim de fornecer subsídios para o direcionamento de esforços por parte dos gestores.

Icaraí continua se destacando como o bairro com maior número de casos confirmados (77 registros). Em termos percentuais, o crescimento da doença em Icaraí foi de $60 \%$. Alguns bairros, porém, apesar de ter números bem menores de casos, mostraram crescimento muito maiores do que Icaraí. 


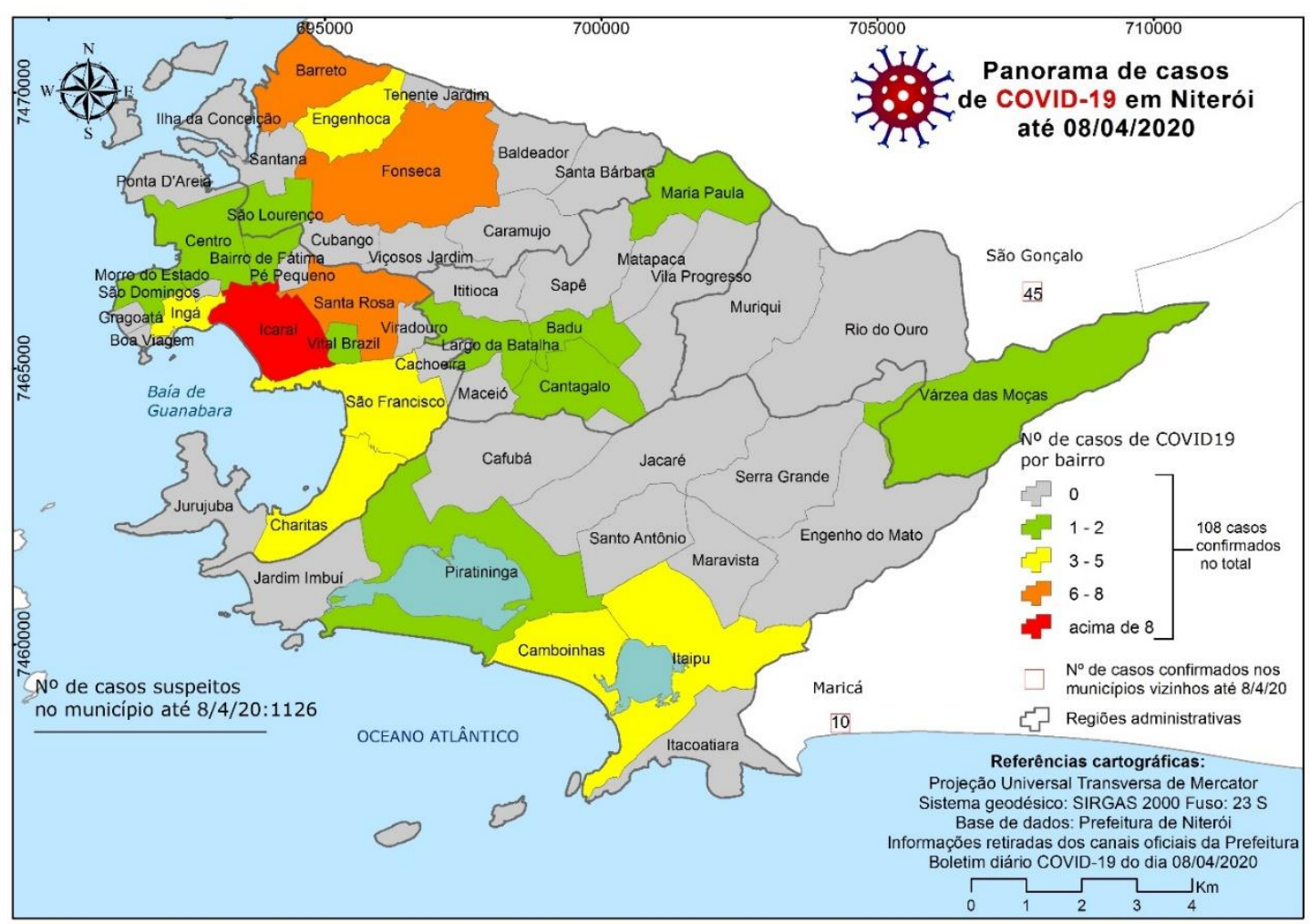

Figura 3: Número de casos de covid-19 por bairros para o município de Niterói em $8 / 4 / 2020$

Fonte: Elaborado pelos autores.

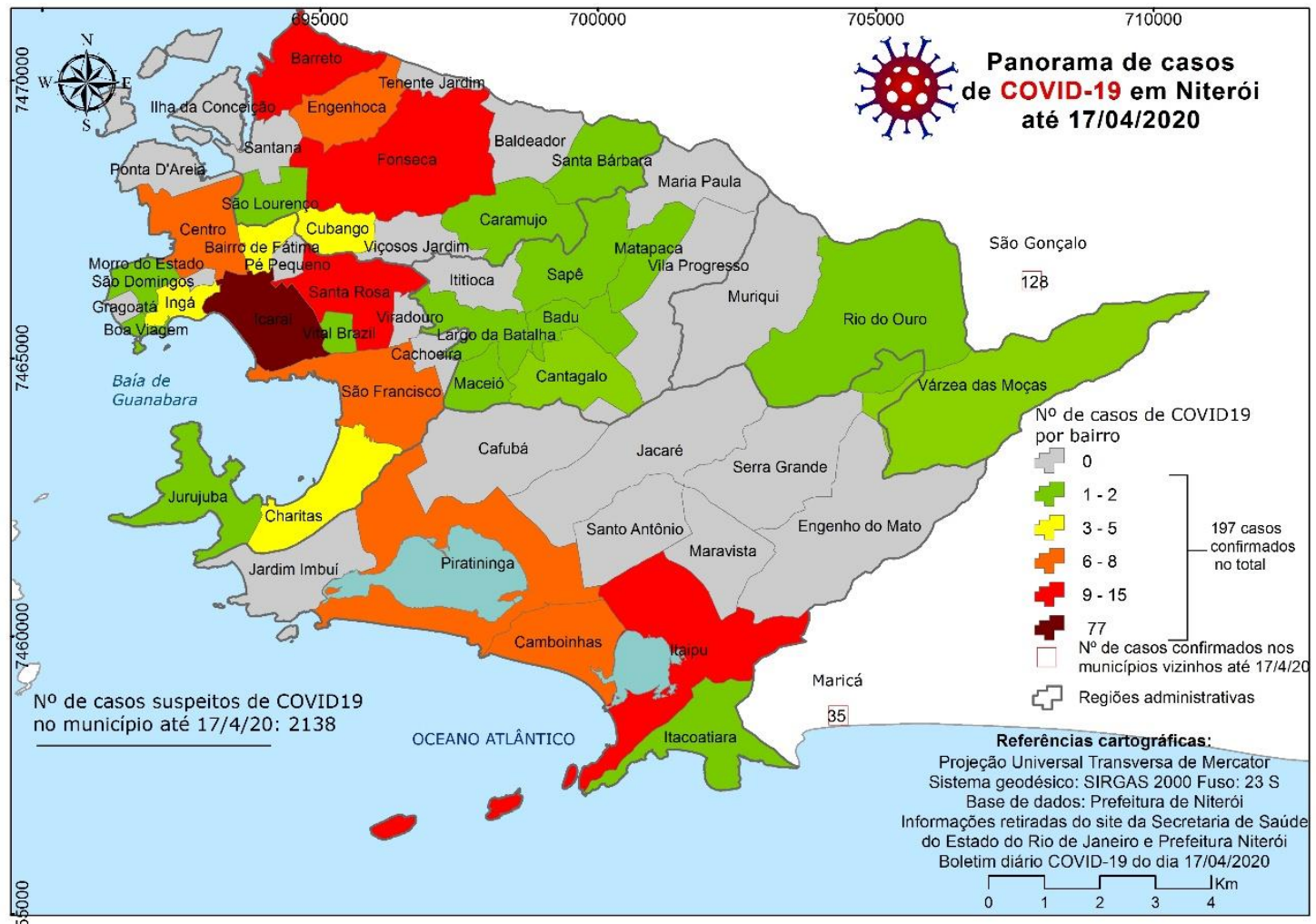

Figura 4: Número de casos de covid-19 por bairros para o município de Niterói em $17 / 4 / 2020$

Fonte: Elaborado pelos autores 


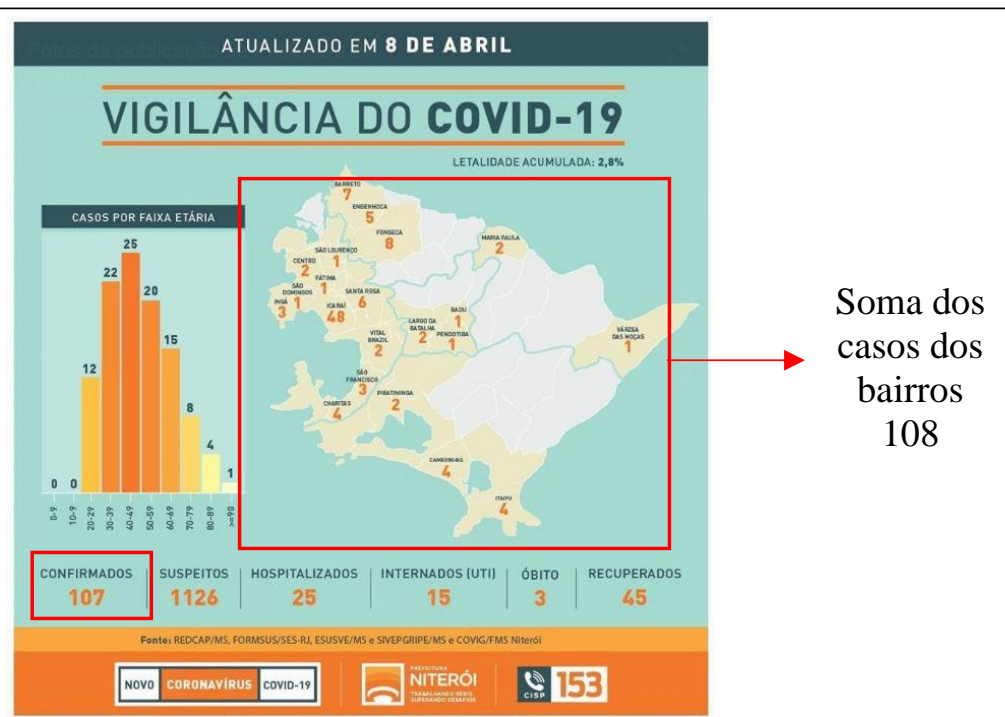

Figura 5: Divergência no Boletim diário do dia 08/04/20

Fonte: Acervo fotográfico dos autores

No Centro, por exemplo, o crescimento foi de $300 \%$, saindo de 2 casos para 8 casos confirmados. Santa Rosa torna-se o segundo bairro em número de casos confirmados, passando de 6 para 15 registros (crescimento de 150\%). Destaca-se que tanto o Centro quanto Santa Rosa são vizinhos de Icaraí. Em seguida mantêm-se Fonseca e Barreto, com 13 e 11 casos (crescimentos de 63\% e 57\%, respectivamente).

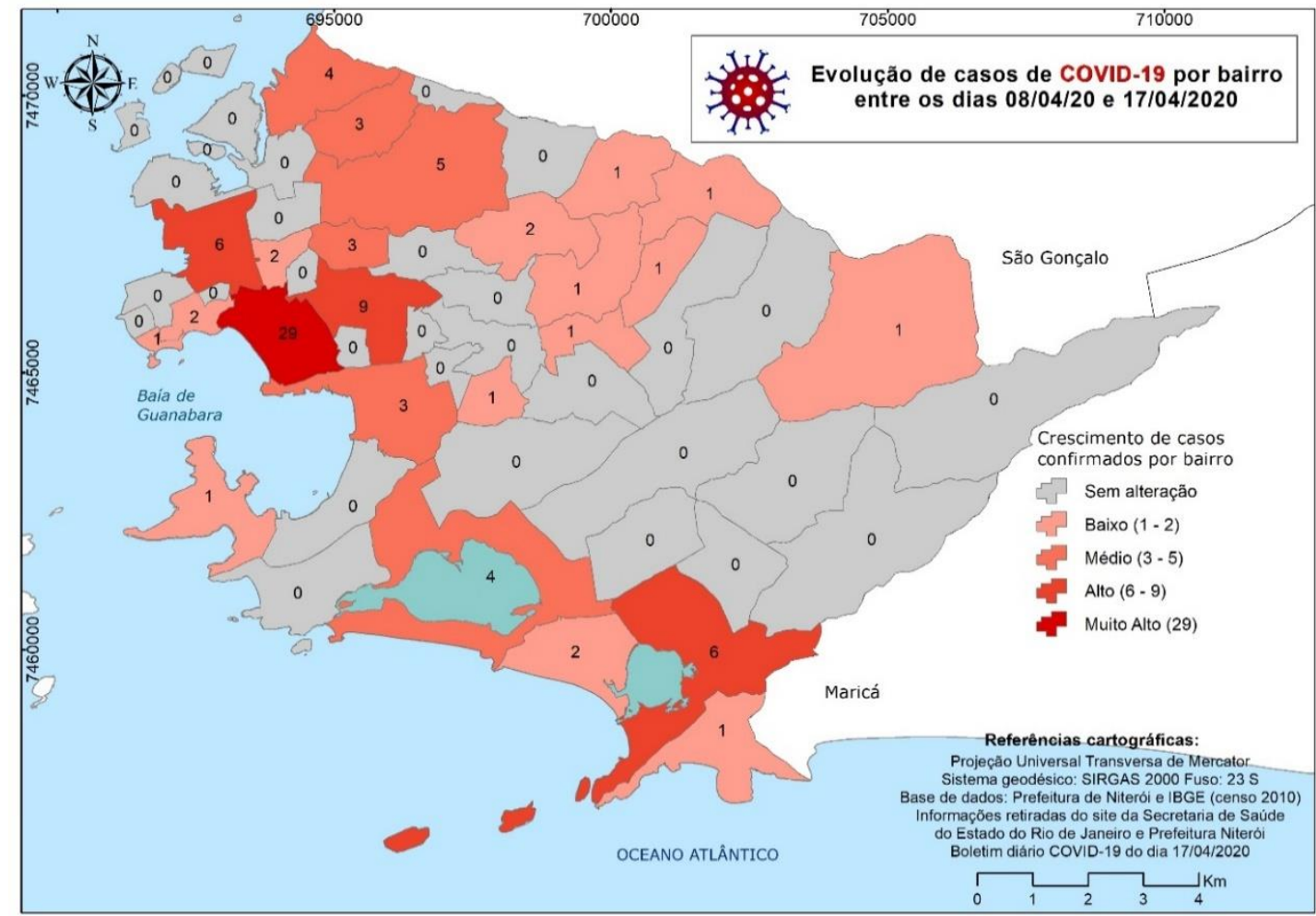

Figura 6: Crescimento no número de casos de covid-19 por bairros para o município de Niterói entre 8/4/2020 e 17/4/2020

Fonte: Elaborado pelos autores

Destaca-se, ainda, Itaipú, com o registro de 10 casos confirmados (contra 4 casos em 8/4), tendo havido uma ampliação de $150 \%$ no número de registros. Com o crescimento dos casos em Itaipu, este bairro pode merecer uma atenção especial por 
causa de sua proximidade com Maricá que ainda apresentava um número pequeno de ocorrências: 35 casos confirmados em 17/4/2020.

Pode-se observar na figura 7, que apresenta os gráficos dos números de casos confirmados, curados e óbitos para os períodos de 11/03/2020 a 08/04/2020 e 11/03/2020 a 17/04/2020, que o crescimento se manteve semelhante. Deve-se considerar, também a ocorrência de subnotificação de casos e/ou associado aos efeitos do distanciamento social e outras medidas preventivas implementadas pela prefeitura, como por exemplo a desinfecção das ruas e passeios.
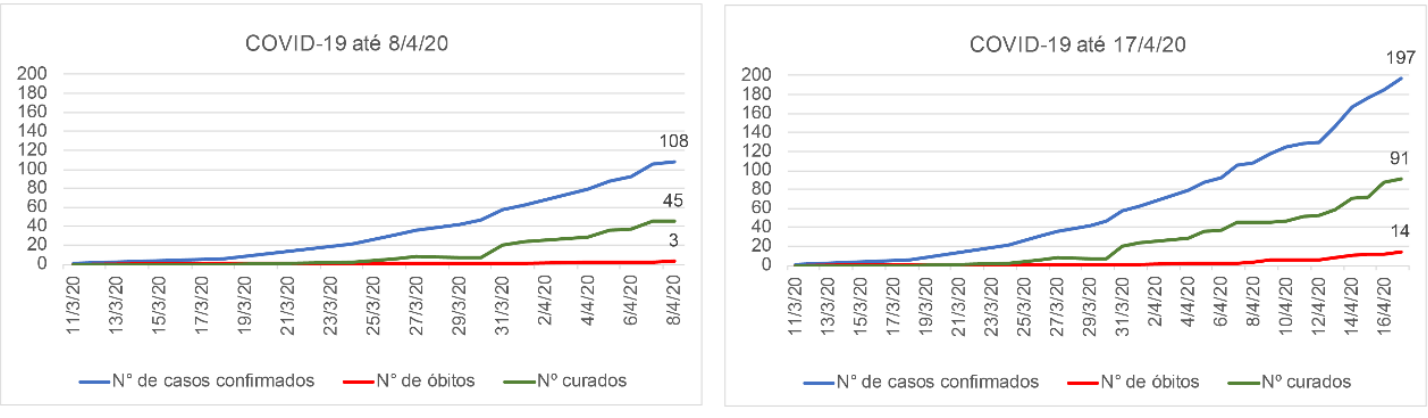

Figura 7: Evolução da covid-19 no município de Niterói, considerando números de casos confirmados, óbitos e recuperados entre 11/3/2020 e 8/4/20202 e entre $11 / 3 / 2020$ e $17 / 4 / 2020$

Fonte: Elaborado pelos autores

Analisando os dados por faixas etárias (figura 8), percebe-se uma pequena mudança nos acometidos pela covid-19. Nas duas datas analisadas a maior ocorrência se dá na faixa de 40 a 49 anos, seguida pelas faixas 30 a 39 anos, 50 a 59 anos e 60 a 69 anos. Enquanto em 8/4/2020 a faixa subsequente em número de casos é a de 20 a 29 anos, em 17/4/2020 há o mesmo número de casos nas faixas de mais de 80 anos e de 20 a 29 anos. Essa é uma diferença importante pois a idade tem se mostrado como um importante fator de risco. Nota-se, ainda, o registro de casos confirmados nas faixas mais jovens de 0 a 9 anos e de 10 a 19 anos em 17/4/2020.
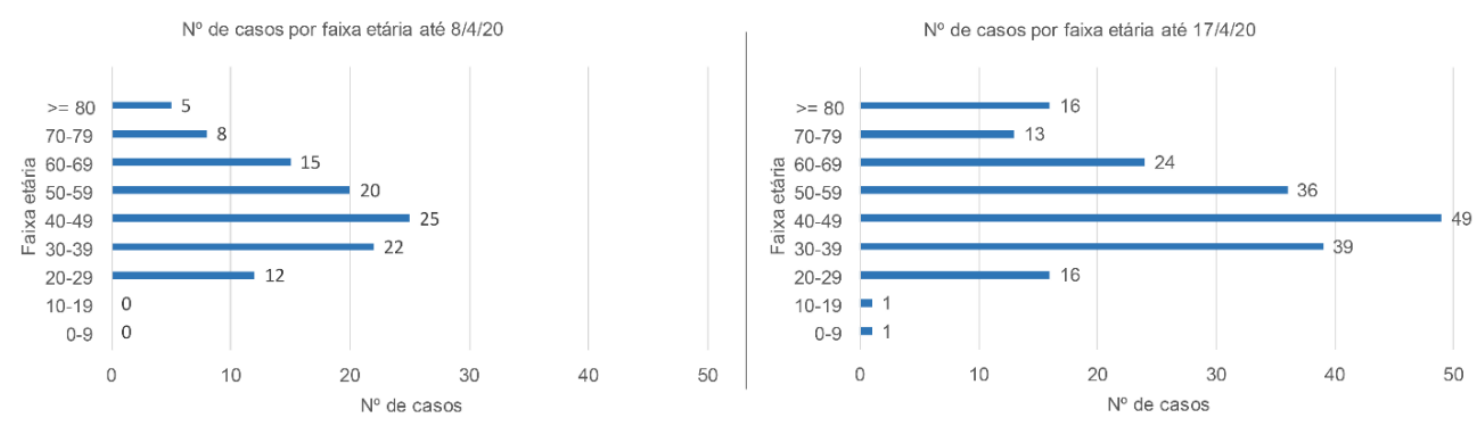

Figura 8: $\mathrm{N}^{\mathrm{o}}$ de casos por faixa etária até o dia 08/4/20 e até o dia 17/4/2020

Fonte: Elaborado pelos autores

Até o dia 8/4/20 o número de idosos (acima de 60 anos) era de 28 casos confirmados, representando $26 \%$ dos infectados. Até o dia 17/4/20 o número de idosos foi de 53 representando também $26 \%$ do total de infectados. O que demonstra que neste período analisado a proporção do número de idosos infectados se manteve em relação ao total de infectados. 
No que tange à distribuição espacial do número de incidências nas regiões administrativas (figura 9), observa-se que a Região Praias da Baía, em ambas as datas, contempla mais de $60 \%$ dos casos confirmados.

Pode-se associar o presente cenário na Região Praias da Baía devido à dois fatores. O primeiro está relacionado à esta região se caracterizar como uma das que apresenta maior adensamento populacional, o que eleva a possibilidade de contágio. O segundo diz respeito à ela contemplar bairros de elevado poder aquisitivo, o que está diretamente relacionado a um maior número de pessoas que possivelmente tiveram contato com o vírus no exterior, seja por viagens à trabalho ou à passeio. Esse último fator é mais significativo na fase inicial desta pandemia.

No entanto, a região que apresentou o maior crescimento percentual foi a Oceânica, totalizando $130 \%$ de casos a mais que na data anterior. Já a região que apresentou menos casos é a Leste, que se deve ao fato da presença de diversas unidades de conservação - como a Reserva Ecológica Darcy Ribeiro e o Parque Estadual da Serra da Tiririca - sendo assim uma área com maior preservação florestal, com menor ocupação urbana, o que diminui a probabilidade de transmissão do vírus.

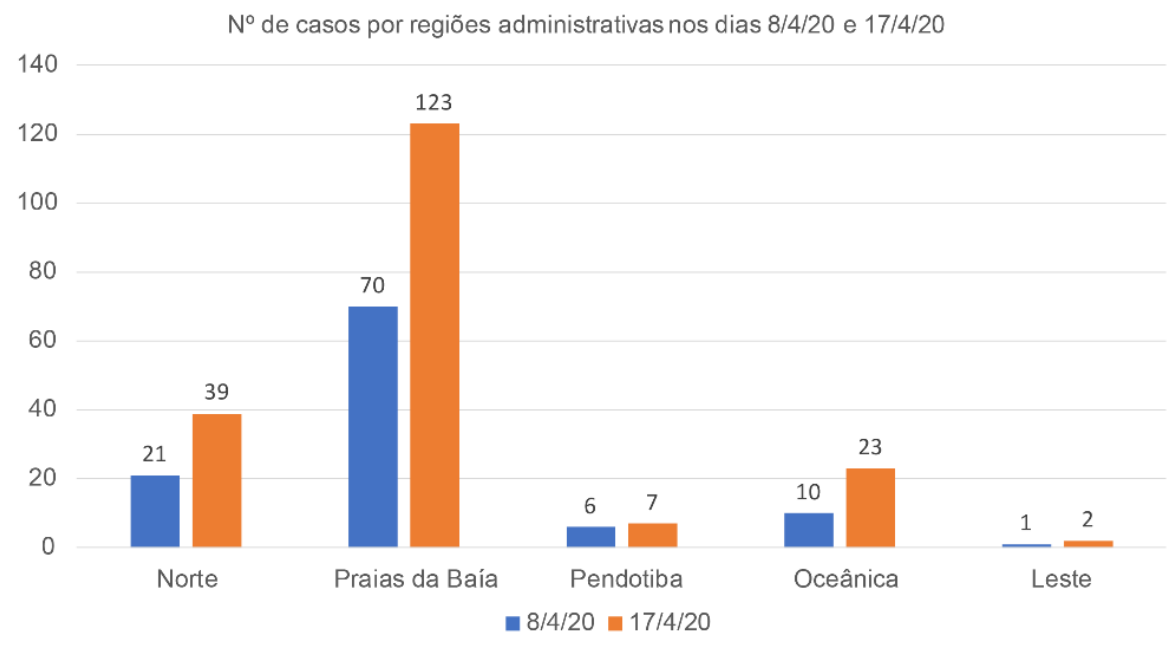

Figura 9: $N^{\circ}$ de casos por região administrativa até o dia 08/4/20 e até o dia 17/4/2020 Fonte: Elaborado pelos autores

\section{Considerações sobre a contribuição de diferentes indicadores sociais e suas interfaces com a suscetibilidade e vulnerabilidade na fase inicial da pandemia}

Na ciência geográfica vem se consolidando nos últimos anos a discussão conceitual, e suas implicações metodológicas, sobre a suscetibilidade e a vulnerabilidade do território a propagação de fenômenos de origem diversas, tanto naturais quanto sociais, ou ainda a junção de ambos. Fundamentada em uma perspectiva sistêmica, nessa abordagem procura-se indicar as interações entre múltiplas variáveis do meio físicobiótico-social e as condições para ocorrência e propagação de determinados vetores de distúrbios nos sistemas. A Geografia física vem usando essa abordagem desde os anos 1960, e mais recentemente foram incorporados vetores sociais para o entendimento dos sistemas ambientais com influência humana, especialmente em áreas urbanas.

Nesse cenário torna-se cada vez mais comum a contribuição da Geografia na gestão de crises motivadas por fatores sociais e/ou naturais quer sejam elas de cunho ambiental, territorial, habitacional ou sanitária. 
Dentro dessa abordagem a Geografia e outras ciências ambientais tem se utilizado de metodologias de análise de suscetibilidade e vulnerabilidade como suporte ao planejamento ambiental e a gestão do território visando contribuir na prevenção e mitigação de problemas diversos característicos de áreas urbanas. Julião et al. (2009) ao abordarem o mapeamento de áreas de risco, indicam que a suscetibilidade está associada à propensão de uma área em ser afetada por perigo, em determinado período de tempo, em decorrência da presença de fatores predisponentes à ocorrência de processos naturais ou induzidos. Nesse sentido as informações socioespaciais são essenciais em estudos de planejamento territorial, pois referem-se à avaliação de suscetibilidade das áreas a serem ocupadas (Santos 2007).

Neste contexto foram avaliados os seguintes indicadores e suas interfaces seja com suscetitibilidade e/ou com a vulnerabilidade da propagação da covid-19 no território: densidade de casos, principais eixos rodoviários de dispersão, rendimento da população por bairro, número de idosos e situação hospitalar no município.

$\mathrm{Na}$ avaliação da transmissividade do vírus é importante identificar as áreas de grande densidade de número de casos a partir da proximidade física e interação funcional. Niterói é limítrofe ao município de São Gonçalo e estabelece com ele tanto relacão de proximidade física (com destaque para os bairros limítrofes os quais, alguns, apresentam o mesmo nome nos dois municípios como Tenente Jardim, Rio do Ouro, Maria Paula e Várzea das Moças) quanto de integração funcional (com grande contingente populacional residindo em São Gonçalo mas estudando, trabalhando, utilizando o sistema de saúde de Niterói).

Na figura 10 pode ser percebido que há uma evolução da densidade de casos entre o dia 08/04/20, 13/04/20 e 17/04/20 nos municípios de Niterói e São Gonçalo. Notase concentração de casos na região Praias da Baía e Região Norte de Niterói (com destaque para bairros como Icaraí, Santa Rosa, Barreto, Engenhoca e Fonseca).

Dada a integração funcional entre os dois municípios é possível perceber na figura 10 uma tendência de dispersão de casos relacionados aos eixos rodoviários tanto da BR-101 quanto das RJ's (RJ-104, RJ-106, RJ-108 e RJ-100). E também das principais vias de circulação interna do município (Estrada Caetano Monteiro, Estrada Fransisco da Cruz Nunes, Av. Roberto Silveira, Rua Marquês de Paraná, Av. Quintino Bocaiúva), constinuindo assim nesta fase da pandemia áreas que contribuem para aumentar a suscetibilidade de dispersão.

É interessante notar o aumento da densidade de casos entre a região norte de Niterói e a região sudoeste de São Gonçalo, entre o dia 08/04/20 e o dia 17/04/20, o qual indica uma tendência de formação de corredor de dispersão integrando os dois municípios nesta área neste primeiro momento de pandemia. Nessas áreas de alta densidade de número de casos, devido à proximidade física e integração funcional, há uma maior tendência à proliferação do vírus.

Um outro foco de casos em crescimento no município de Niterói, entre o dia 08/04/20 e 17/04/20 são os bairros de Itaipu, Camboinhas e Piratininga, localizados na Região Oceânica do município.

Um indicador que pode aumentar a suscetibilidade à dispersão do vírus é o fluxo de pessoas que viajam a trabalho ou mesmo a passeio para nações com grande número de casos de covid-19 (principalmente Europa, Estados Unidos e China), o que está relacionado diretamente à renda. Na figura 11 pode ser percebido que o bairro de Icaraí é um dos bairros que apresentam o maior percentual de população com renda acima de dez salários mínimos, entre 14 e 26\%, o que se constituiu em um fator possibilitador para ser um dos bairros primeiramente atingidos. Segundo Ferrão (2020) as regiões com dinâmicas transfronteiriças mais intensas ou as áreas que mantêm uma circulação regular 
de pessoas com comunidades emigrantes estão mais expostas à possibilidade de importação de vírus.

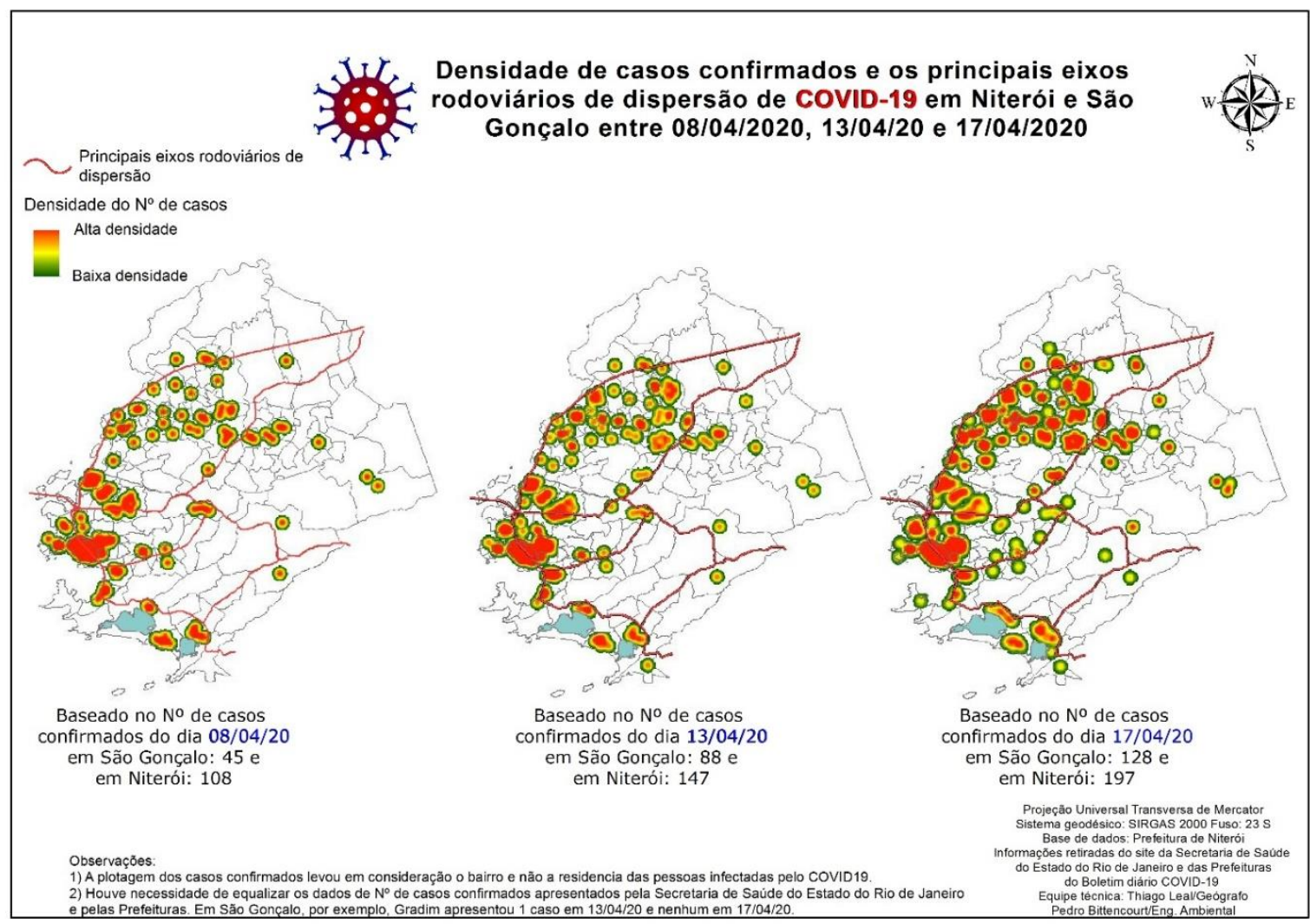

Figura 10: Densidade de casos confirmados e os principais eixos rodoviários de dispersão

Fonte: Elaborado pelos autores

Devido à diminuição dos voos internacionais e medidas de restrição adotadas no município (como distanciamento social) a preponderância dos casos vinculados com países infectados ou com pessoas infectadas provenientes de outros países diminuiu. $\mathrm{O}$ que fez com que o Ministério da Saúde no dia 20 de março de 2020, na portaria $\mathrm{n}^{\circ}$ 454/2020, declarasse que o Brasil estava saindo de um quadro de transmissão local (quando pessoas mesmo sem terem estado em nenhum país com registro da doença, se contaminam através do contato de uma pessoa que trouxe o vírus de fora do país) para um quadro de transmissão comunitária nacional ou transmissão sustentada (quando o contágio ocorre dentro de um determinado grupo de pessoas numa dada localidade, sem que o portador da doença tenha estado em países com casos confirmados).

O Núcleo de Métodos Analíticos para Vigilância em Saúde Pública PROCC/Fiocruz e EMAp/FGV (2020) nesta mesma direção indica que o número de casos importados internacionalmente tende a diminuir sua relevância frente aos casos decorrentes de transmissão comunitária sustentada na ausência de ações de mitigação efetivas. 


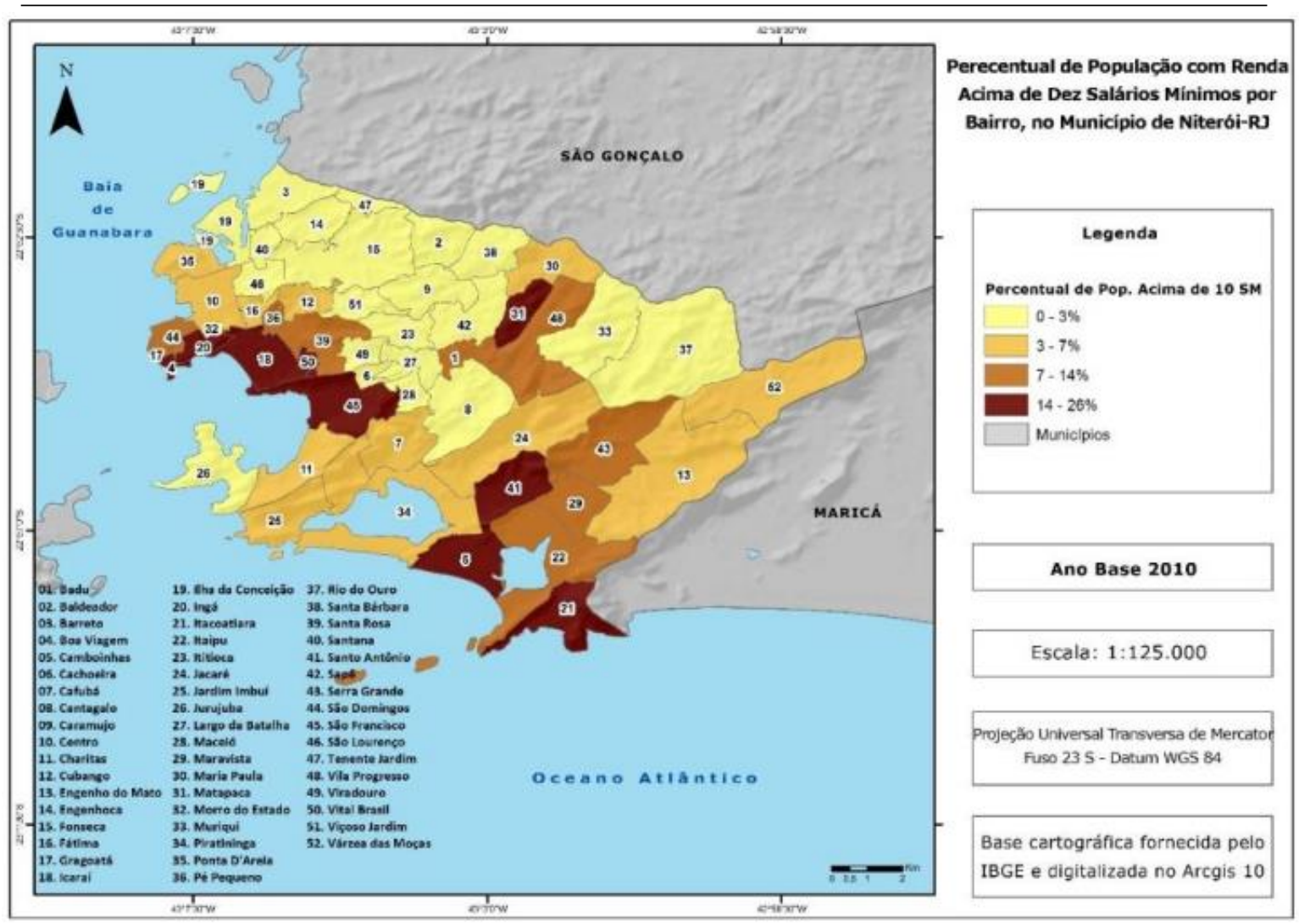

Figura 11: Percentual de População com renda acima de dez salários mínimos por bairro.

Fonte: Drumond, R. (2018)

E nesta fase de transmissão sustentada em Niterói o vírus tende a se disseminar seguindo os padrões de mobilidade interna na cidade, como foi visto na figura 10.

A figura 11, além de indicar a porcentagem da população com alto rendimento por bairro, também revela a desigualdade social e consequentemente o alto grau de vulnerabilidade social de alguns bairros que apresentam apenas de 0 a $3 \%$ da população acima de 10 salários mínimos, ao analisar por setor censitário certamente a realidade seria mais representativa indicando dentro de um mesmo bairro a preponderância do $0 \%$. A diferença de renda está diretamente relacionada ao acesso a serviços hospitalares e clínicos, à possibilidade de ficar em distanciamento social, ao acesso a informação e aos produtos de proteção (álcool em gel, sabonete, máscara, entre outros).

A localização dos grupos de renda em determinados bairros da cidade relacionase, entre outros aspectos, à diferente capacidade que cada grupo possui de pagar tanto pela casa ou terreno, quanto pelos equipamentos e serviços coletivos. Somente os que desfrutam de determinada renda podem morar nas áreas bem servidas de equipamentos coletivos. Os que não podem pagar, são empurrados para as periferias subequipadas, as áreas suburbanas, as áreas centrais deterioradas e para os loteamentos ilegais (RODRIGUES, 1988).

Outro indicador que interfere na vulnerabilidade é o número de idosos por bairro (pessoas acima de 60 anos). Como são considerados grupo de risco locais com esssas características devem receber redobrada atenção, uma vez que quanto maior o número de idosos infectados, maior tende a ser o risco de elevação no número de internações e de óbitos. Com base nos dados do censo demográfico do IBGE (2010) foi confeccionado um mapa representando o número de idosos por bairro em Niterói (figura 12). Icaraí que apresenta o maior número de casos confirmados de covid-19 (77 casos) também apresenta 
o maior número de idosos (com 18852). Em segundo lugar no número de idosos está o bairro do Fonseca que está em terceiro lugar no número de casos confirmados (13 casos).

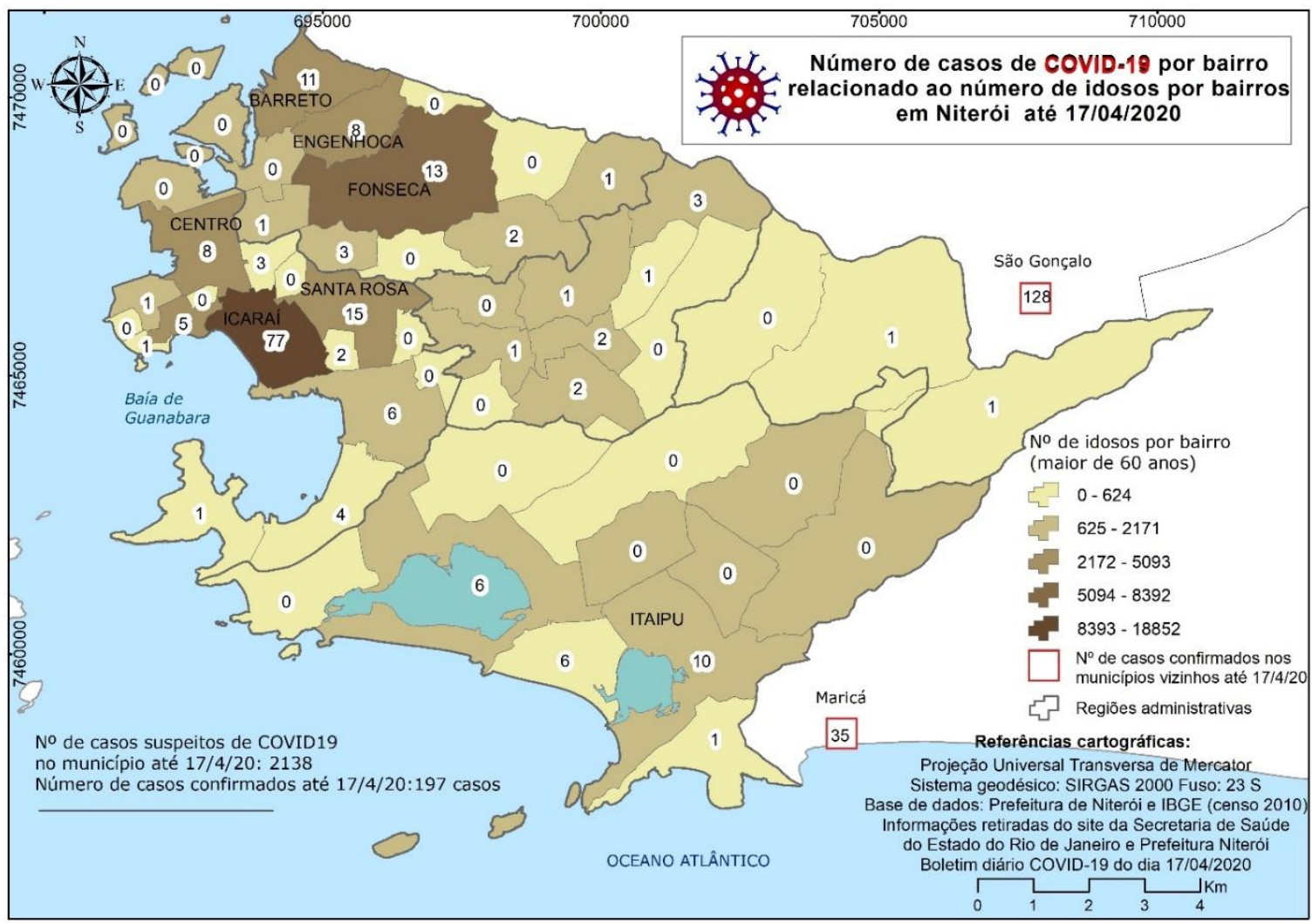

Figura 12: Número de casos confirmados de covid-19 por bairro associado ao número de idosos por bairro.

Fonte: Elaborado pelos autores

A situação hospitalar é outro indicador que também se relaciona à vulnerabilidade, uma vez que quanto maior o número de pessoas na UTI ou na enfermaria menor é a capacidade do tratamento pelo sistema de saúde e maior tende a ser o número de óbitos. Cabe ressaltar que diferente dos outros fatores que apresentam resultado por bairro, este é um dado relacionado ao município como um todo, mas que interfere diretamente na fragilidade dos bairros com o avanço da doença.

Em relação à situação hospitalar dos casos confirmados, observa-se na figura 13 uma queda de $7 \%$ do percentual daqueles que necessitaram de internação na UTI, isto para um aumento de aproximadamente $82 \%$ do número total de casos confirmados do dia 08 de abril para o dia 17 de abril de 2020 (89 casos a mais). Já a proporção dos hospitalizados na enfermaria manteve-se estável, caindo em apenas $1 \%$ em relação à data anterior.

Importante acrescentar que segundo a Prefeitura de Niterói (2020) foi arrendado um hospital particular, com a finalidade de ser o primeiro hospital público do Brasil a oferecer 140 leitos com respiradores e unidades de tratamento intensivo exclusivos para a covid-19. O acompanhamento dos casos somados a medidas mitigadoras é fundamental para contenção dos efeitos adversos durante a pandemia, o que contribui para diminuir a letalidade da doença.

Segundo MMWR - Morbidity and Mortality Weekly Report - (2020), setor relacionado ao Departamento de Saúde e Serviços Humanos dos EUA, as diferenças geográficas no número de casos e mortes de covid-19, a incidência cumulativa de casos 
e as mudanças de incidência provavelmente refletem uma combinação de fatores epidemiológicos e de nível populacional específicos de cada área, incluindo 1) o momento da introdução SAR-CoV-2;2) densidade populacional; 3) distribuição etária e prevalência de condições médicas subjacentes entre pacientes com covid-19; 4) o momento e a extensão das medidas de mitigação da comunidade; 5) capacidade de teste de diagnóstico; e 6) práticas de notificação de saúde pública.

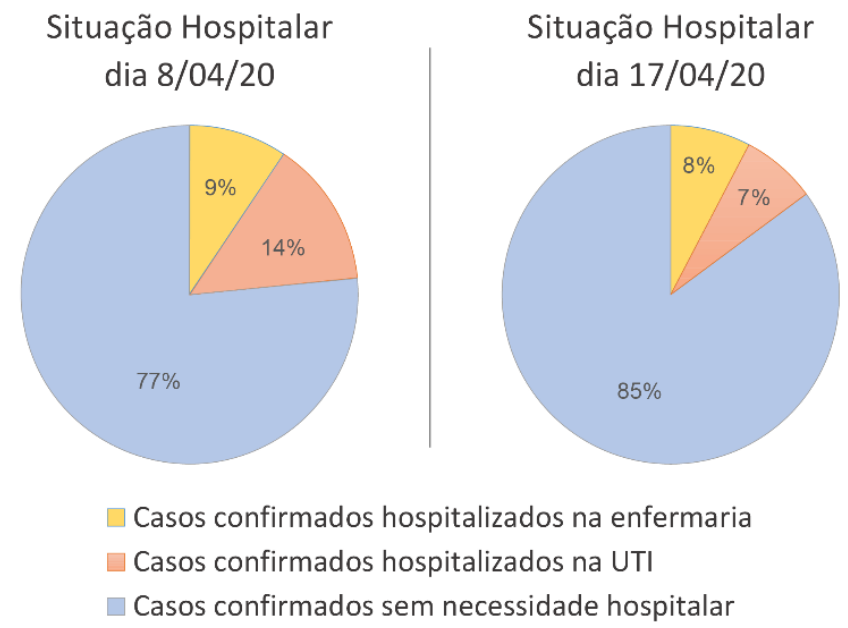

Figura 8: Situação hospitalar até o dia 08/4/20 e até o dia 17/4/2020

Fonte: Elaborado pelos autores

Dentre esses pode ser acrescentado ainda: o grau de interação funcional entre cidades, a proximidade física com as áreas de grande densidade de casos e o tipo de urbanização (relacionado diretamente à renda e o tipo de construção) em áreas de grande densidade demográfica.

\section{Considerações finais}

Considera-se relevante a contribuição da Geografia com o uso de geotecnologias na análise da distribuição espaço-temporal da covid-19 no contexto intrametropolitano do estado do Rio de Janeiro nesta fase inicial de propagação. A reflexão sobre as características geográficas para a propagação do covid-19 em Niterói alcançou o objetivo proposto.

Nesta fase inicial até dia 17/4/20 da covid-19 em Niterói há uma concentração de casos confirmados nos bairros de Icaraí, Santa Rosa, São Francisco, Centro, Itaipu, Camboinhas, Piratininga, Fonseca, Engenhoca, Barreto. Dada a proximidade física de São Gonçalo, Fonseca, Barreto e Engenhoca apresentam tendência de se tornar o novo pólo de densidade de casos do município.

Importante neste contexto é frisar que diferente de Niterói que tem adotado várias medidas mitigadoras (distanciamento social, obrigatoriedade do uso de máscaras, distribuição de kits de limpeza nas comunidades, sanitização das ruas e testagem em massa), São Gonçalo apresenta uma política pública menos incisiva, com ações tímidas. $\mathrm{O}$ que pode fazer com que o descontrole de uma unidade federativa interfira na gestão do sistema de saúde de outra.

Outro bairro que merece atenção nesta fase inicial é Itaipu dada a evolução do 
número de casos no período analisado e a possibilidade de sofrer interferência ou de interferir em Maricá, principalmente o bairro de Itaipuaçu.

A análise não restrita ao município, mas levando em consideração a integração funcional entre cidades ajudou a observar a dinâmica da proliferação do coronavírus nas áreas de divisa, indicando os bairros de alta suscetibilidade de propagação.

A avaliação por diferentes critérios e multitemporal, proposta na metodologia, contribuiu para buscar como os indicadores sociais estudados apresentam interface com a suscetibilidade e vulnerabilidade gerando subsídios para o entendimento sobre a origem e condições de propagação da pandemia. Podendo ser replicado ou mesmo aprimorado o uso desses indicadores em outras unidades político-administrativas do Brasil, sejam estados ou municípios. A escala temporal de dias foi muito importante para indicar o desenvolvimento da pandemia nesta fase inicial.

Há uma limitação inerente aos dados primários usados. Os dados demográficos utilizados nesta pesquisa são do censo do IBGE de 2010, ou seja, um lapso temporal de 10 anos. Assim é fundamental a realização dos censos de $10 \mathrm{em} 10$ anos obedecendo a série histórica visando uma melhor representatividade do território brasileiro e consequentemente da dinâmica populacional.

Niterói adquiriu 40 mil testes rápidos para detecção da covid-19 o que pode provocar um aumento exponencial em relação ao número de casos analisados neste trabalho, dado o grau de subnotificação até o presente momento, principalmente dos casos assintomáticos.

Dada a complexidade da temática é importante o desenvolvimento de estudos mais aprofundados. Sugere-se para trabalhos futuros além da utilização da unidade de bairro, usar também a unidade de setor censitário ou até mesmo de grade estatística do IBGE. A grade estatística tem sido disponibilizada pelo IBGE desde 2016 e espacializa os dados de número de domicílios e população total e por sexo sob forma de grade de 200X200m em áreas urbanas e 1000X1000m em áreas rurais. Representar os dados por setor censitário ou por grade estatística permitiria identificar variações dentro dos bairros. Isso seria ainda mais importante nos bairros com maior número de casos confirmados, buscando encontrar as possíveis dinâmicas da proliferação a partir de pontos potenciais de contágio como supermercados, farmácias, bancos, etc.

\section{Referências bibliográficas:}

BRASIL. Atlas do Desenvolvimento humano no Brasil. 2013. Disponível em: <http://www.atlasbrasil.org.br/2013/pt/mapa/>. Acesso em: 20 abril 2020.

BRASIL. Ministério da Saúde. Coronavírus Brasil. Painel. Disponível em: <https://covid.saude.gov.br/>. Acesso em: 25 abril 2020.

CASTRO, Cleber Marques de; PEIXOTO, Maria Naíse de Oliveira \& RIO, Gisela Aquino Pires do. Riscos Ambientais e Geografia: Conceituações, Abordagens e Escalas. Anuário do Instituto de Geociências - UFRJ, Rio de Janeiro, Vol. 28, N 2 , p. 11-30, 2005.

CARVALHO, Tatiane Robaina Rangel. Suscetibilidade a Processos Geodinâmicos e Aptidão à Urbanização na Bacia do Rio Maracujá, Ouro Preto- MG, 2014. Dissertação (Mestrado) - Universidade Federal de Ouro Preto. Escola de Minas. Núcleo de Geotecnia - NUGEO. 2014. 
DRUMOND, Rafael Carvalho. A cidade de Niterói: Política urbana, valorização do solo e habitação. In. XV Seminário de História da Cidade e do Urbanismo, 15², 2018, UFRJ. Anais do XV Seminário de História da Cidade e do Urbanismo. Rio de Janeiro: Even3, 2018.

FERRÃO, João. A geografia da COVID-19: algumas precisões. Jornal Público, Lisboa, 16 de abril de 2020. Disponível em: <https://www.publico.pt/2020/04/16/sociedade/opiniao/geografia-covid-19precisoes-1912527>. Acesso em: 20 abril 2020.

IBGE. Cidades. Disponível em: <https://cidades.ibge.gov.br/brasil/rj/niteroi/panorama/>. Acesso em: 25 abril 2020.

MMWR, Morbidity and Mortality Weekly Report. Geographic Differences in COVID-19 Cases, Deaths, and Incidence - United States. February 12-April 7, 2020. Rep 2020;69:465-471. DOI: http://dx.doi.org/10.15585/mmwr.mm6915e.

Núcleo de Métodos Analíticos para Vigilância em Saúde Pública (PROCC/Fiocruz e EMAp/FGV). Estimativa de risco de espalhamento da COVID-19 no Brasil e avaliação da vulnerabilidade socioeconômica nas microrregiões brasileiras. 2020. Acesso em 25/04/20 Disponível em https://bibliotecadigital.fgv.br/dspace/bitstream/handle/10438/28942/procc-emapcovid-19-reporte2_20200323vulnerabilidade $\% 20 \% 281 \% 29$.pdf? sequence $=2 \&$ isAllowed $=\mathrm{y}$.

PREFEITURA DE NITERÓI. Prefeitura de Niterói terá primeiro hospital exclusivo para tratamento do coronavírus no país. 20/03/2020. Acesso em 23/04/2020. Disponível em: http://www.niteroi.rj.gov.br/index.php?option=com_content $\&$ view $=$ article $\& i d=65$ 10:2020-03-21-22-27-17

RODRIGUES, Arlete Moysés. Moradia nas Cidades Brasileiras. São Paulo: Contexto, 1988. $74 \mathrm{p}$.

SEABRA, Vinicius da Silva; CAMPOS, Andrelino de Oliveira; MODESTO, Nilo Sérgio d'Ávila; NETO, Duclerc Siqueira; CORREIA, Mariana Ribeiro; COSTA, Evelyn de Castro Porto \& SANTOS Arthur Alves Bispo. Análise da distribuição da população por diferentes unidades de representação: um estudo de caso para o município de Niterói-RJ. Espaço \& Geografia, Vol. 18 No 1, 2015.

US Department of Health and Human Services/Centers for Disease Control and Prevention. Geographic Differences in COVID-19 Cases, Deaths, and Incidence United States, February. Morbidity and Mortality Weekly Report, EUA, Vol. 69, N ${ }^{\circ}$ 15, p. 465-471, 17 abril 2020. 